\title{
Engineering, Design and Gender: A Review of Approaches and Possible Influences.
}

\author{
Brian Burns - Associate Professor \\ School of Industrial Design, Carleton University, Ottawa \\ brian_burns_eng@carleton.ca
}

\begin{abstract}
This paper is intended to promote discussion of the human processes involved in Engineering and Design. For the convenience of discussion, a distinction is proposed, between 'sex' and 'gender' - 'males and females' and 'masculine and feminine'. Recent work studying the participation of female students in the currently male dominated profession of engineering is reviewed. The paper thus explores engineering and design, left-handedness, hunting and gathering, communication, collaboration, sustainability, nurture, holistic thinking, the Kyoto Accord, and how developments in the masculine and feminine aspects of design and engineering may well be essential to the future of Design Engineering.
\end{abstract}

\section{Introduction}

The establishment of the Canadian Design Engineering Network is part of the essential evolutionary development of the practice of Engineering and Design. Significantly, the name CDEN - which connects the terms Design and Engineering, indicates some mutual exclusivity and acknowledges the need to extend the Engineering profession by forging a link. This and similar conferences are intended to help us move forward, sharing our knowledge and our ignorance, and identifying opportunities and breaking down false barriers.

This paper is intended to be discussive in nature, and asks the reader to be forgiving in the brief evaluation of issues of gender that follow. The author is very well aware of the sensitivities involved and of the considerable literature and debate concerning such issues.
In recent years alongside the development of Engineering education has come interest in the number of female students studying Engineering at University; the general feeling being that more female students should be enrolled. The aspiration to have $50 \%$ female students in engineering programs has already been matched in my field of Industrial Design. In recent years the program here at Carleton has enrolled well over $50 \%$ female students, who continue to do well in a program that was, in the past, male dominated. For the past few years we have monitored our enrolment numbers within an application procedure that is, by its nature, gender neutral. The questions that arise in our deliberations involve such issues as, the lack of Design and Technology Studies in schools, the perception that subjects related to Design and Technology lead 'merely' to 'blue collar' careers, questioning if current course patterns lead to more males than females being able to attain appropriate admission grades and courses, etc.

However, behind these significant issues lies the issue of gender and the dangerous question - 'Why does Engineering and Design need more female students?'

First responses are obvious - the need for equal opportunity is fundamental, hopefully to bring about parity with equal pay for equal work, and other basic human rights issues. Without question these are fully merited concerns. But, the question, 'What can female students bring to Engineering and Design?' remains.

Clearly, while we all - male and female - tend to share some fundamental abilities, we each have differing abilities and aptitudes. We hope that education and social development can enable all talents to be detected and built on. However, there are differences. As an educator in Industrial Design, I am well aware of my abilities and, I hope, my limitations. Hopefully I have found my calling. The challenge in my career 
development was, as I assume it is for all of us, to match my aptitudes and abilities with appropriate socially desirable tasks and challenges. The path is rarely smooth but hopefully I have reached that place where, as the adage suggests, "I can stand to do what I have to do on a bad day".

This conference will hopefully shed light on the challenge of marrying Design and Engineering. This paper will hopefully shed some well-meaning light on the challenge of marrying Gender Issues with Engineering and Design.

\section{Terms of Reference}

It is difficult to attempt any such review of gender issues without encountering serious opposition. This is a sensitive matter. In her book "Gender Trouble", Judith Butler [1] tackles concerns over the indeterminacy of gender, and the possible failure of feminism. In so many cases such discussion leads to 'trouble', which she bravely sees as part of the ongoing process. With her text, and many of a similar nature, there is an implied differentiation between the terms 'sex' and 'gender'. She states that 'Gender is the repeated stylization of the body, a set of repeated acts within a highly regulatory frame that congeal over time to produce the appearance of substance, of a natural sort of being" and continues to identify politically signified and maintained individual and social boundaries. Her opening chapter concludes with the intention of her book - "This text continues, then, as an effort to think through the possibility of subverting and displacing those naturalized and reified notions of gender that support masculine hegemony and heterosexist power, to make gender trouble, not through strategies that figure a utopian beyond, but through the mobilization, subversive confusion, and proliferation of precisely those constitutive categories that seek to keep gender in its place by posturing as the foundational illusions of identity".

In the preparation of this paper the author has encountered many contrary views, and has found limited work concerning the benefits of gender in Engineering and Design professions. So, to continue the 'trouble-making' of Judith Butler this paper continues with the differentiation between 'sex' and gender' as a means to explore potential challenges and opportunities.

The Oxford Dictionary [2] offers 'sex' as the division into which living beings are placed - male and female. In contrast 'gender' pertains to qualities corresponding roughly to the two sexes and sexlessness - masculine, feminine and neuter. This differentiation is taken here as the stepping of point for the discussion that follows. As the boundaries continue to blur between men and women, the issues of masculinity and femininity continue to offer significant food for thought.

This paper uses the terms 'masculine' and 'feminine' qualitatively, as characteristics or patterns of behaviour that may or may not pertain to men and women. It may be that men display more of what is being termed here, masculine traits than women, and vice versa, but it is the benefits of those traits that this paper is attempting to explore.

To help illustrate this position some parallels will be considered.

\section{Left-Handedness}

Left-Handedness is not seen as a gender issue, but it has caused considerable social concerns over the years. In the not too distant past such a physical bias was the subject of considerable prejudice [3], particularly in hand-writing. It is physically more difficult to push a pen nib across the page when writing from left to right, yet there have been many successful left-handed calligraphers. The predominance of right handed people means that many products are designed for the right-handed. Until recently left-handed scissors were very scarce. In some cases left-handedness has been seen as an advantage, in many sports for example, where lefthandedness can change the patterns and angles of action. But we are not all left-handed or right-handed. Some are indeed ambidextrous. Most of us may well favour one hand over the other, but do not undertake all activities with the same bias. We may in fact be $80 \%$ right-handed and $20 \%$ left-handed. The capacities of Leonardo da Vinci in this regard are well documented, with suggestion that his use of his left hand was often as relaxation following other righthanded activities. It could be argued that the use of a computer mouse in the left hand would cause less shoulder strain with current keyboards that extend further to the right of the 'Qwerty' section. Driving on the left and right hand side of the road seems to cause few dexterity problems, with hands able to operate gear levers on either side; though interestingly the foot peddles have been standardised to favour the dominant right foot. In the world of Ice Hockey 'shooting right' or 'shooting left' does not naturally correlate with right or left-handedness. 
Like gender issues, 'handedness' has caused 'trouble' and slowly we have learned to, first, tolerate, then take advantage of the benefits it can offer. The author suggests that issues of masculinity and femininity, while causing 'trouble', can offer considerable benefits if considered appropriately.

\section{Language}

The English language is a neutral language, in that it does not carry with it direct reference to 'masculine, feminine, and neuter'. Early in the preparation for this paper the masculinity and femininity of certain words were looked at in both French and Italian. The following words seem to offer interesting insights:

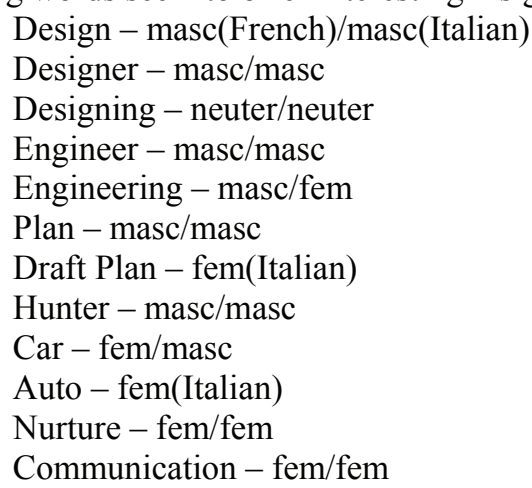

This brief reflection was not intended to be extensive, though the author invites the reader to undertake such a study in other languages. The intent is perhaps to identify characteristics, that may be part of a historic false barriers, which may require some 'trouble making, or may relate to some opportune characteristics.

Just as I might not be wholly right-handed, it might be fair to acknowledge that I am not wholly masculine. I may possess a dominant array of masculine characteristics, but there may also be a significant array of feminine ones too.

\section{Is Engineering masculine?}

The tendency to characterise masculine attributes as strong and tough is easy to understand. Historically, the role of the male to be the strong hunter/gatherer, while the female took on the nurturing role is stereotypical. That masculinity and femininity would evolve from that is understandable; likely requiring some deserved 'trouble-making' along the way.
However, the achievements of this masculine dominated profession are remarkable. The utilisation of resources and ingenuity over the past two thousand years has taken the western world to increasingly high levels of wealth. The need for basic survival was long ago laid to rest as we built - hunted and gathered - our modern world. We live now in a world of interconnectedness. Every action has implications. Professions like Engineering cannot operate in a vacuum. Such functional hunting and gathering has led us, today, to the awareness of the finite nature of our planet and the resulting need for the Kyoto Accord. Global standards are common. Projects have to be undertaken holistically in teams. The consequences of failure can be daunting and potentially disastrous. As Buckminster Fuller and the founders of CDEN acknowledged we need a 'Design Revolution', and that cannot be undertaken solely by masculine hunter/gathering. To move forward we need to work in teams with good communication - a feminine characteristic?

\section{Language and Communication}

The word 'Design' was originally used in the creation of a plan. Today it is often seen in North America as a reflection of 'style' and 'fashion'. At the same time we talk of the 'Design Process' as a means to evolve or develop a better solution. Often this term is merely interpreted as another form of product development. The goal for engineering all too often remains in the functionality - sadly the roots of the word engineering laying in parallel with 'genius' and 'ingenious' are often forgotten.

In contrast, most texts on Design Methods [4] suggest the use of a range of design activities - User Trips, User Research, Information Searches, Objectives Trees, Counterplanning, Interaction Matrices, Interaction Nets, Brainstorming, Classification, Forced Connections, New Combinations, Enlarging the Search Space, Functional Innovation, Performance Specification, and of course, Checklists. All involving teamwork and clear communication. In researching this paper the author spoke to successful female engineers. The discussion often led to the need for some 'trouble-making' often resulting from poor decision making, planning and communication skills. Are these feminine characteristics? This would clearly need further authoritative research. There is, however, existing work to help in the process. 


\section{Gender and Collaboration}

In 2002, Sandra Ingram and Anne Parker [5] undertook a study into collaboration styles in the Engineering Classroom. This was an excellent study reviewing the success and failure of mixed groups of students, male and female, undertaking a range of engineering activities. Their work responded to the many studies that have highlighted the concerns over a lack of communication skills in Engineering students.

Their work concluded - "The study does not lend support to the existence of distinct gender-based interactional styles as identified in the literature: that is, there was no clear differentiation between a feminine style of communicating, usually seen to be nurturing, relationship-focused and consensual, and a male style, normally described as more competitive and assertive".

Overall, the study did not directly differentiate between male/female and masculine/feminine characteristics. It did, however, highlight the success of one of the team leaders, Todd, who, by his approach exemplified the ways in which goals can be met. The study implied somewhat of a surprise at the success of Todd's team. It may well be that collaborative communication is a feminine characteristic, however, Todd showed that he possessed that characteristic, amongst his many others.

Their work concluded that while the role of gender in influencing team dynamics is worthy of further investigation, their study found that it exerts less impact on the collaborative process than other factors such as team commitment and work ethic. Todd's example demonstrated the characteristics of the "androgynous collaborator", and his success suggested that the more traditional male (masculine) and female (feminine) attributes can be combined in one individual.

While it is clear that the lack of communication/collaboration skills needs be addressed, success might be more a result of correctly assembling a team with the right attributes, hopefully a balance of masculine and feminine, rather than a balance of male and female.

\section{Engineering, Design and 'Kyoto'}

In recent years, through issues of resource depletion, global warming, holes in the ozone layer and the realisation of global interdependency, we have learned that the future cannot be seen as a mere extension of past practices. Though simplistic, it is reasonable to see our past efforts as exploitive; the extension of the hunter/gatherer model. For the purpose of this paper such practices could be seen as stereotypically masculine. The Kyoto Accord is concerned with our survival - in a sense, an attempt to help us adopt more nurturing practices. The author makes no attempt to prove these points, merely to note the need for a differing approach. Through Kyoto we are identifying new challenges - the future of Engineering and with it the need for Design and collaboration. The need for a holistic approach, with greater balance between the expoitive and the nurturing - the masculine and the feminine.

\section{Discussion}

This paper was never intended to discourage or encourage male or female students from enrolling in any program. The use of the terms masculine and feminine can easily be identified with males and females. Perhaps it would be better to choose other terms in the identification of the attributes essential to the undertaking of any task. The author could find no appropriate alternative terms in the literature. Perhaps it is better to stay with the terms we have established to date. For that, the differentiation between masculinity/femininity and male/female does appear to have some merit.

In undertaking any task it is important to first identify the required activities and the characteristics of the people who will undertake them successfully. That we know as part of successful team-building. The challenges facing Engineering involve a greater involvement in design and communication. Our environmental concerns must be met by a holistic balanced response. The Engineers of tomorrow must be equipped to meet that challenge.

In trying to identify how such skills and awareness can be developed in Engineering education and practice, the model of masculinity and femininity attributes might be worthy of consideration. The perfect well rounded Design Engineer of the future will need a balanced array of attributes, both masculine and feminine. How much of Engineering will be masculine and how much feminine is purely conjectural. In fact, the author sees no reason why the terms should be used at all, and the make-up of future Engineering Schools and Departments may well have a varied balance of males and females. What is fundamental is 
that they have the right attributes for the task at hand, some masculine(?) and some feminine(?). Perhaps Engineering will continue to be one of the more masculine professions - how many males? - how many females? The success of Engineering and Design engineering, in particular, will be measured by how well the practitioners are educated to tackle the challenges ahead.

\section{References}

[1] Judith Butler, "Gender Trouble - Feminism and the Subversion of Identity", Routledge, New York, 1990

[2] F.G. and H.W. Fowler, "The Oxford Dictionary", Clarendon Press, Oxford, First Edition 1924

[3] Michael Barsley, "Left-Handed People", Hal Leighton Printing Company, USA, 1967

[4] Nigel Cross and Robin Roy, "Design Methods Manual", The Open University Press, Milton Keynes, UK, 1975

[5] Sandra Ingram and Anne Parker, "Gender and Collaboration - Communication Skills in the Engineering Classroom”, Fernwood Publishing, Halifax, 2002 